Original Research Paper

\title{
A Fuzzy Decision Support Model for Cropland Recommendation of Food Cropping in Indonesia
}

\author{
${ }^{1}$ Ditdit Nugeraha Utama, ${ }^{2}$ Alvali Zaqi Taufan, ${ }^{2} \mathrm{Al}$ Ghifari Hartzani, \\ ${ }^{2}$ Hasfhi Haidi, ${ }^{2}$ Yusuf Ramadhan Lubis and ${ }^{3}$ Wahyu Sardjono \\ ${ }^{1}$ Computer Science Department, BINUS Graduate Program - Master of Computer Science, \\ Bina Nusantara University, Jakarta, Indonesia 11480 \\ ${ }^{2}$ Department of Information System, UIN Syarif Hidayatullah, Jakarta, Indonesia \\ ${ }^{3}$ Information Systems Management Department, BINUS Graduate Program- \\ Master of Information Systems Management, Bina Nusantara University, Jakarta, Indonesia 11480
}

Article history

Received: 02-01-2020

Revised: 11-02-2020

Accepted: 28-04-2020

Corresponding Author:

Ditdit Nugeraha Utama

Computer Science Department,

BINUS Graduate Program -

Master of Computer Science,

Bina Nusantara University,

Jakarta, Indonesia 11480

Email: ditdit.utama@binus.edu

\begin{abstract}
Indonesia has an incredibly wide area for agriculture. The agriculture area in Indonesia has specific characteristic for each area (e.g., water capacity, land porosity, land height, etc.,). Furthermore, food crop is the most plant planted in Indonesia; rice, corn, red bean, green bean are some important food crops. The study aims to create a Decision Support Model based on fuzzy logic (FDSM). The model is able to recommend the most suitable food crop to be rationally planted in a specified area. The recommendation is based on distance value between plant and area characteristic value. Two main methods are operated in this study, they are fuzzy logic and Euclidean distance measurement. The method fuzzy logic purposely avoids the ambiguity of parameter value and considers the human linguistic based parameter value. Afterward, the Euclidean distance adopted to calculate the fitness value as a fundamental value for decision recommendation. Here, seven geographic parameters (i.e., water availability, temperature, humidity, land height, land slope, rainfall and land porosity) matched to food crop's biotic parameters in finding the fittest value. Finally, the model shows a simulation of recommendation for 514 administrative areas of 34 provinces' district/municipality (in Indonesia) based on five types of food crops (i.e., rice, maize, soybeans, green beans and peanuts).
\end{abstract}

Keywords: Fuzzy Logic, Decision Support System, Euclidean Distance, Food Crop, Indonesia

\section{Introduction}

Global food security is robustly correlated to climate issue, limitation of land available for agriculture and food crop production topics. Such a global food security is progressively challenging in line with population escalation (Ma et al., 2018). The escalation drastically influences the future worldwide cropland loss (Wu et al., 2018). Correspondingly, the food crops powerfully depend on the quality of planting land and environment; e.g., water and zinc content in land (Noulas et al., 2018), land cover (Liu et al., 2018), dryness of cropland (Echchelh et al., 2018), etc.

In particular, the studies with topic food crops relating to numerous aspects have been methodically done by several researchers. For example, Meinen et al., (2018), who tried to inter-connect the aspect of environment condition with vegetable crop management. The conditions considered in the study were harvesting process, light and temperature; radiation and gravity were not taken into account in this research. The study result said that the fresh food production is able to be increased by utilizing spread harvest and enlarging plant density.

Furthermore, Richardson and Moskal (2016), who studied the link between food crop production and urban forest. Richardson and Moskal (2016) constructed a geospatial method which is able to logically approximate an optimal capacity of city's food production. In this study, the effect of urban tree canopy in reducing the capacity of food production was also modeled. The result stated that the tree shadow decreases a capacity of food crop production between 19\% until 35\%. The study was conducted in city Seattle, USA. 
Moreover, Khan et al. (2013) performed a research to see the interconnection between wastewater irrigation for food crops and human health in Pakistan. Wastewater irrigation for food crops has a high negative risk to human health. The risk is triggered by consuming food crop contaminated with toxic heavy metal (e.g., cadmium, lead and chromium), where the contamination occurs in wastewater irrigation for food crop. The result of study recommended that the country's authority institution has to treat and monitor wastewater irrigation system routinely and periodically.

Also, Tai and Martin (2017) developed a statistical model to measure a food crop yield sensitivity to ozone air pollution and temperature extremes. The study findings exhibited the importance of counting ozone regulations as a promising strategy to practically enhance future food security. It also estimated that the US wheat, soybean and maize production is going to fall off by $13 \%, 28 \%$ and $43 \%$ respectively.

Likewise, Rodda et al. (2011) conducted a research to benefit grey-water for irrigation of food crops and also its link in contributing to food supply and informal income. Three factors were observed in this study, they are crop yield, nutrient level and plant growth; and two types of crop were taken as study object: An above-ground crop (i.e., Swiss chard) and a below-ground crop (i.e., carrot). Three point are taken as a study's conclusion: Grey-water increased plant growth and yield, grey-water irrigation improved the level of nutrient content in crop and electrical conductivity and metal concentration of grey-water irrigated soil escalated.

As well, Thompson and Meyer (2013) studied an impact of the second generation biofuels to food security. For the purpose, Thompson and Meyer (2013) developed an economic model. The model showed that the biofuel market affects food price; however it depends on policy procedure and market environment, where biofuel from crop residues is going to decrease food price possibly. Or Abid et al. (2016) who studied a correlation between climate change and food productivity in Pakistan. It aimed to explore the adaptation of wheat farmer to climate change, its effect to food yield and income. Here, the method logistic regression analysis was systematically benefited. The study result said that the farmer well aware of climate change. Numerous adaptations they do are changing crop varieties, fertilizer types and planting date.

Based on the background above, the high significance of food crops for human life and the importance of appropriate land for food copping in Indonesia; the study is realized finally. It is profound study regarding the contribution of computer science in agriculture. The study systematically illuminates a constructed decision support model based on the principal method fuzzy logic (FDSM) for objectively suggesting the most suitable food crop to specific cropland for food cropping purpose in Indonesia. Seven geographic parameters (i.e., water availability, temperature, humidity, land height, land slope, rainfall and land porosity) and five types of food crops (i.e., rice, maize, soybeans, green beans and peanuts) are taken as object of the study. The model's simulation is going to academically give a recommendation for 514 administrative areas of district/municipality for 34 provinces (in Indonesia) regarding the proper food crop to be planted in a precise location.

\section{Literature Review}

\section{Decision Support Model}

A Decision Support Model (DSM) is a model which is able to support the decision maker in deciding a specific decision objectively. Particularly in agriculture field, Chen and $\mathrm{Wu}$ (2019) proposed a DSM in commodity trading problem. It was constructed to maximize a sustainability of NGO's supporting program dynamically.

Also, Han et al. (2019) develop SIMAGRI. It is a DSM that can help a decision maker in making a strategic or tactical decision in crop production. It was developed to translate climate information into agricultural and economic terms. Several decisions suggested by model are planting dates, crops and cultivars choices, etc. Then, Topping et al. (2019) constructed a DSM for forecasting a management consequence on various species across landscapes. It is an answer to solve a multi-criteria decision-making problem in specifically agriculture area.

Furthermore, Wadhwa et al. (2019) developed a mathematical model for making decision in investment for developing domestic container stations of grain production. The study performed for case of soybean container deliveries in Minnesota region.

\section{Model for Food Crops}

Various researchers have developed a technical model or approach to optimize the production of crops, specifically for food crops. For instance, Chen et al. (2018) proposed a novel approach to map large-scale croplands, cropping pattern and planted area of crop type in Brazil. Three types of crop were operated in the study; soy, cotton and maize. The study utilized 2015-2016 time series data of Moderate resolution Imaging Spectroradiometer (MODIS).

Additionally, Pacetti et al. (2017) developed a new method to evaluate the impact of flood on food supply. In this study, Pacetti et al. (2017) academically combined agricultural statistics and water footprint databases and remote sensing data. The method was 
applied in two case studies; in Bangladesh (2007) and Pakistan (2010). The study results said that the flood (as the most impacting natural disaster on agriculture) influenced food sup-ply reduction between $5 \%$ until $8 \%$.

Then, Bandara and Cai (2014) constructed a model to examine the impact of climate change to crop productivity, food price and food security, specifically in five countries in South Asia: India, Nepal, Bangladesh, Sri Lanka and Pakistan. The model was developed based on a "global dynamic computable general equilibrium". Its simulation showed that there was major negative impression of climate change to agriculture productivity, it is going to be a massive trouble for food security.

Finally, Osama et al. (2017) technically created a linear optimization model which considers irrigation water necessities, crop yield, crop types and food needs to maximize the annual return of Egypt. The model simulation said that the gross net benefit is declining, then the model proposed a new cropping pattern to improve the Egypt's gross net return without adding any other costs. Or Neethirajan et al. (2018) technologically made biosensor platform for monitoring the expanse of pathogens and food-borne disease, as pathogen infections are able to downgrade a quality of food production and cause danger to biodiversity. The platform is able to be exploited to examine and fabricate safe food.

\section{Research Method}

The study was conducted in three stages with specific objectives defined and individual methods operated in each stage. It is configured clearly in Fig. 1. Firstly, the literature study and preliminary analysis (to understand the study comprehensively) were conducted thru using the method desk based study. In this stage, numerous manuscripts of a number of journals coming from online databases (e.g., sciencedirect, etc.,) that are correlated to topics decision support model, cropland and food cropping were systematically reviewed.

Also, the case was learned in this first stage preliminarily. It was done on purpose to discover the central problems. Here, the difficulty and complexity in determining the most appropriate food crop for one precise agriculture area (in Indonesia) is the vital problem, as the suitable food crop planted in one suitable agriculture land is conceivably going to give the optimal yields. Such a situation will make Indonesia's agriculture condition better and more beneficial.

In the second stage, the parameters/constraints and data were determined. They were done to determine and select the data and parameters. Here, we processed parameter values thru the conception of fuzzy logic and Monte Carlo.

The method fuzzy logic is functioned to avoid the bias in measuring value of parameters. The constructed model utilizes the bias value as input of modeling.

Principally, the fuzzy logic is not fuzzy. It is an exact logic of vagueness and approximate reasoning (Zadeh, 2008). Its primary contribution is delivering a foundation for an evolution from binarization to graduation, binarism to pluralism (Zadeh, 2015). It has a crucial capability to correctly reason with imperfect information that is uncertain, incomplete, vague, or partially true due to one specific condition (Zadeh, 2009). At some point, the information is acquired from subjective opinion. Practically, the method fuzzy logic was also ever operated by (Utama et al., 2017a) and (Utama et al., 2017b) in several studies regarding smart and intelligent system topic.

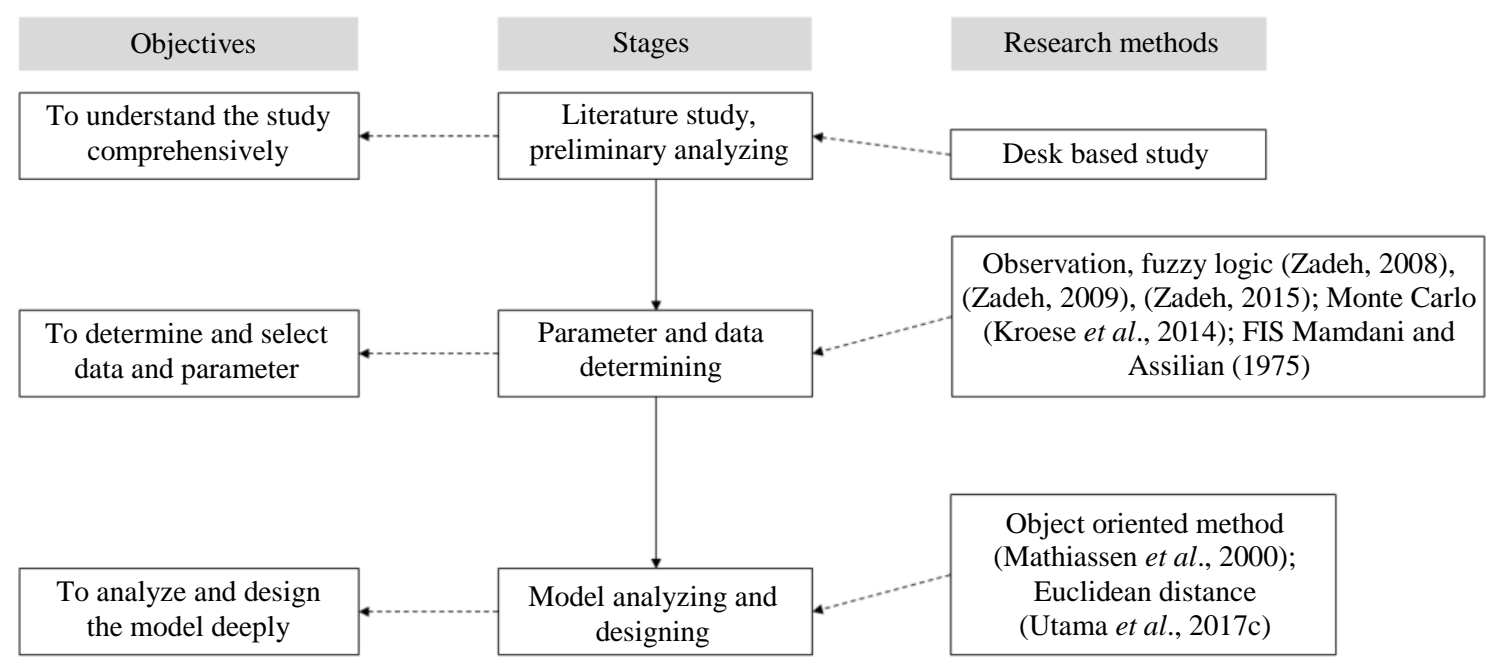

Fig. 1: The research stages 
Moreover, the idea of fuzzy rule base is also operated to exclusively determine the value of parameter 'water availability' via the conception of Fuzzy Inference System (FIS). Here, the model Mamdani and Assilian (1975) is used to technically implement the FIS; where three fuzzy difference methods are occupied (i.e., max, additive and probabilistic). Then, to realize the mathematical computation based on FIS Mamdani model, software Mathlab is operated.

The, the observation was used to seek the data required. Data limitation is challenging to conduct the study. The authorized institution does not fulfil all $(100 \%)$ data required. For the purpose of model simulation, we benefitted approximately $90 \%$ empirical data (based on climate-data.org institution) to generate 3,084 dummy data by using the method Monte Carlo. Principally, the method Monte Carlo is a type of algorithm to obtain numerical results (based on repeated random sampling) and commonly operated for three aims; i.e., optimization, numerical integration and number generating (Kroese et al., 2014). Then, we validated the dummy data via adjusting the empirical data as an edge for each parameter value generated. The validation done to make all data used in simulation realistic and representative. It is beneficial to improve the constructed model's validity.

The third step of the study is model analysis and design, surely to analyze and design the model in detail. The main method benefited here is object oriented approach (Mathiassen et al., 2000). Several tools are officially functioned; e.g., class diagram, usecase diagram, activity diagram, etc. The class diagram describes the interconnected entities involve in the model. Academically, one entity is represented by class configuration containing of three parts: Name, attributes and operations. The usecase diagram depicts high level design of the constructed model portraying the communication pattern between model and actors (both human and non-human/system actors). Then, the activity diagram is detailed explanation of usecase diagram. Here, usecase as a group of operation is tried to be explained in more detail. In the activity diagram, the condition and status of process are clearly illustrated.

Moreover, the calculation method of Euclidean distance (Utama et al., 2017c) is operated to identify the fitness value between ideal condition for food crop growth and land characteristics. The smallest distance value denotes the nearest distance, it implies the most suitable and it means the supposed food crop is very suitable to be reasonably planted in the supposed land:

$$
\begin{aligned}
& d(p, q)=d(q, p)=\sqrt{\sum_{i=1}^{n}\left(q_{1}-p_{1}\right)^{2}} \\
& d(p, q)=\sqrt{\left(q_{1}-p_{1}\right)^{2}+\ldots+\left(q_{n}-p_{n}\right)^{2}}
\end{aligned}
$$

Regarding the method Euclidean distance computation, the fundamental formula to calculate a distance of two points in Euclidean n-space is represented in Equation (1), where $\mathrm{d}$ represents Euclidean distance, $p$ is point $p$ and $q$ is point $q$. The mathematical expression in Equation (1) is called as Pythagorean formula (Anton, 1994). Mathematically, it can be defined in more detailed like in Equation (2).

As the best value us commonly epitomized by the highest value, thus the minimum relative value (Utama et al., 2016) of distance is operated also here. It is the value taken from the compassion between the most minimum value of distance and the current distance value. The arithmetical formula is unambiguously expressed in Equation (3); where $R V_{\text {min }}$ symbolizes a minimum relative value and $V_{C}$ characterizes a current value:

$R V_{\text {min }}=\frac{\min \left(V_{1} \ldots V_{n}\right)}{V_{c}}$

\section{Results and Discussion}

\section{Parameterization}

Seven topographical parameters are considered to evaluate the condition of one agriculture area (planting land). The interconnection among parameters in the constructed model is configured thru the influence diagram (Fig. 2). Officially, four parameters (i.e., Rainfall, Land Porosity, Land Slope and Land Height) are functioned to directly determine water availability. Here, the parameter Water Availability is a dependent parameter, as it is determined based on other parameters. The parameter water availability with other two (i.e., Temperature and Humidity) are collaboratively functioned in the constructed model. In this case, the constructed model is going to advise the best combination between cropland and food crop which will be planted.

The influence diagram (Fig. 2) also illustrates the sub-models involved in the main constructed model. It shows there are two sub-models here; mathematical and fitness models. Surely, we cannot avoid the mathematical model in developing a computer model, thus such a sub-model is a part of main model. The other one is the fitness sub-model. It is assembled based on two fundamental approaches: Fuzzy logic and Euclidean distance conception. Finally, the influence diagram portrays the objective of the main model executed. In this study, the objective of the model developing is to optimize the crop yield, in this case it is Indonesian food crop productivity. 


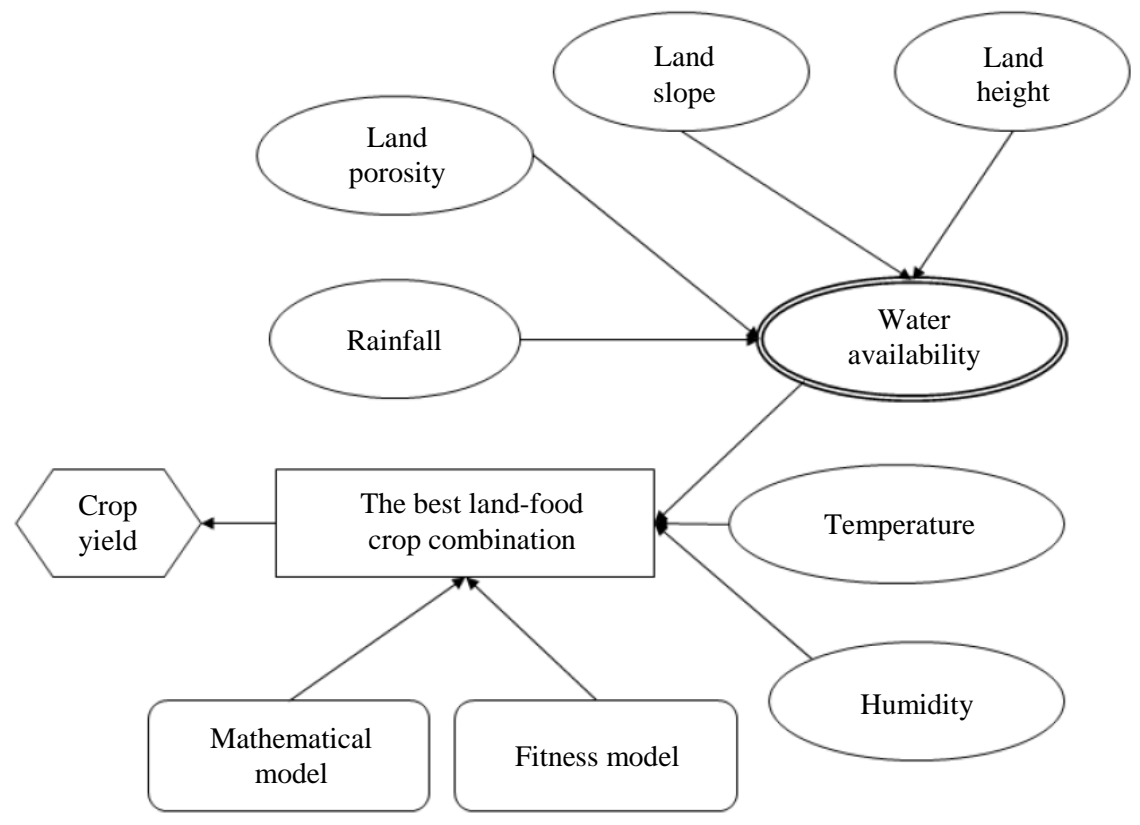

Fig. 2: The Influence diagram for interconnected parameters, sub-models and the constructed model's objective

All parameters used are determined thru the conception of fuzzy logic. They are specifically defined via fuzzy triangular membership function with specific limitation of linguistic variable. The parameter Rainfall $\left(\mathrm{mm}^{3}\right)$ is defined with three linguistic variables: Low (L), Middle $(\mathrm{M})$ and High $(\mathrm{H})$; with respectively triangular limits $(0,0,1800),(1200,2400,3600)$ and $(3000$, $4800,4800)$. The membership function of parameter Rainfall is described in Fig. 3. The rainfall value (commonly stated in unit $\mathrm{mm}^{3}$ ) means a capacity of rain falling in one restricted area/region in one time (moment) (Dairaku et al., 2004).

The parameter Land Porosity (\%) is also classified via fuzzy triangular membership function with three linguistic variables: Small (S), Middle (M) and Large (L). The triangular limits for describing the variables $\mathrm{S}$, $\mathrm{M}$ and $\mathrm{L}$ are $(10,10,15),(10,20,30)$ and $(25,30,30)$ respectively. The picture that describes the fuzzy triangular membership function for parameter Land Porosity is Fig. 4. The land porosity (normally quantified in unit \%) expresses the volume of land (or ratio) which is able to absorb the water (Anovitz and Cole, 2015).

Furthermore, the fuzzy triangular membership function for describing the parameter Land Slope $\left(^{\circ}\right.$ ) is depicted by Fig. 5. There are three types of linguistic variable as well (flat/F, sloping/Sl and steep/St) which are defined with triangular membership values: $(5,5$, $15),(10,20,30)$ and $(25,35,35)$. The parameter Land Slope (usually quantified in unit o) indicates the gradient or incline of the land (Young, 2016).

Then, the parameter Land Height (m) is defined as well by fuzzy triangular membership function (Fig. 6).
Three types of linguistic variable functioned are Low $(\mathrm{L})$, Middle (M) and High $(\mathrm{H})$. They are in theory ranged by triangular limits $(200,200,550),(350,700,1100)$ and $(900,1200,1200)$.

\section{Listing 1. Examples of Fuzzy Rule Base}

IF (Rainfallishigh) AND

(Land Height is low) AND

(Land Slope is flat) AND

(Land Porosityislarge) THEN

Water Availability is Much

ELSE IF (Rainfall is high) AND

(Land Height is low) AND

(Land Slope is flat) AND

(Land Porosity is small) THEN

Water Availability is Middle

ELSE IF (Rainfall is high) AND

(Land Height is low) AND

(Land Slope is steep) AND

(Land Porosity is middle) THEN

Water Availability is Little

ELSE IF (Rainfall is middle) AND

(Land Height is low) AND

(Land Slope is flat) AND

(Land Porosity is large) THEN

Water Availability is Much 


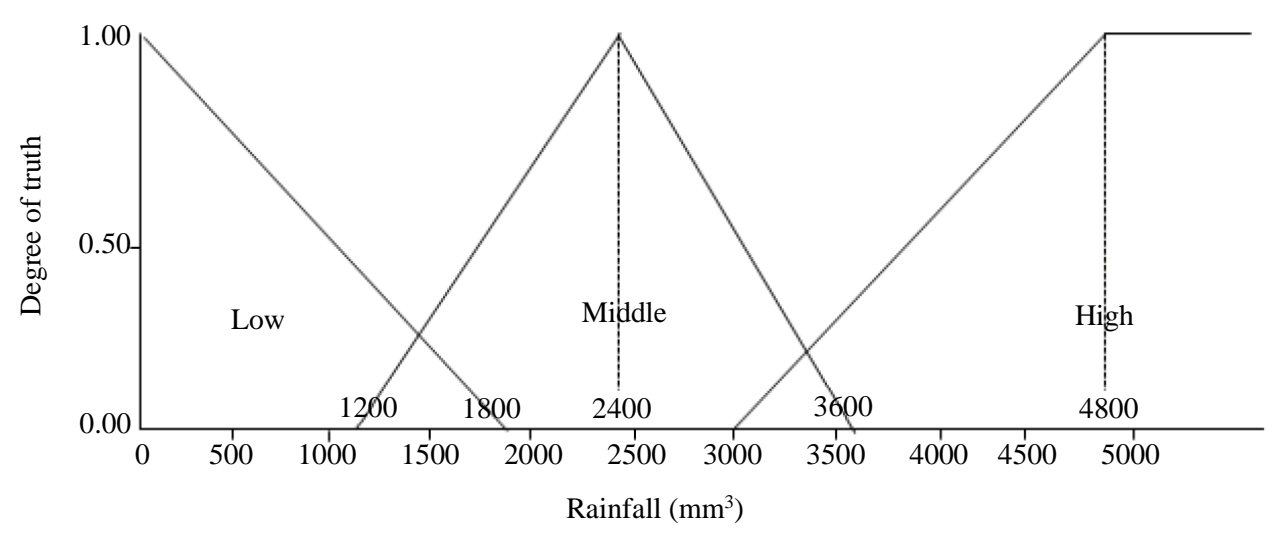

Fig. 3: The graph of fuzzy triangular membership function for rainfall

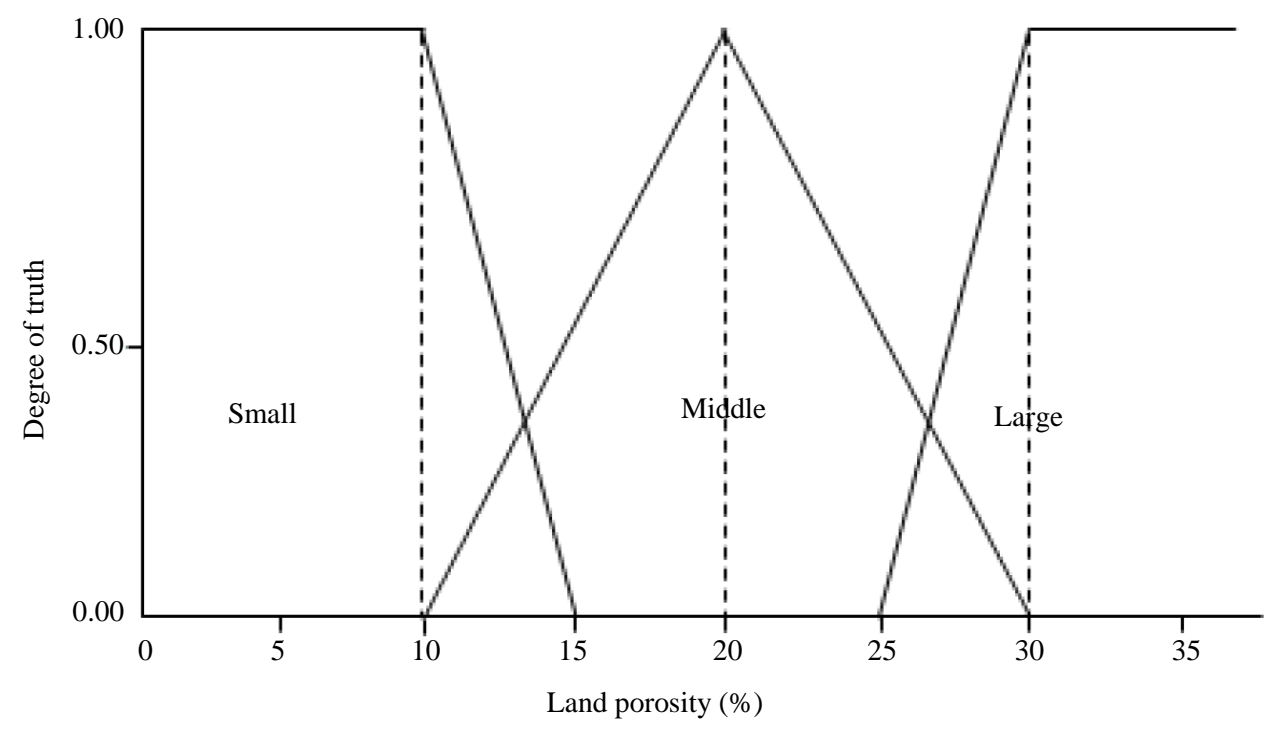

Fig. 4: The graph of fuzzy triangular membership function for land porosity

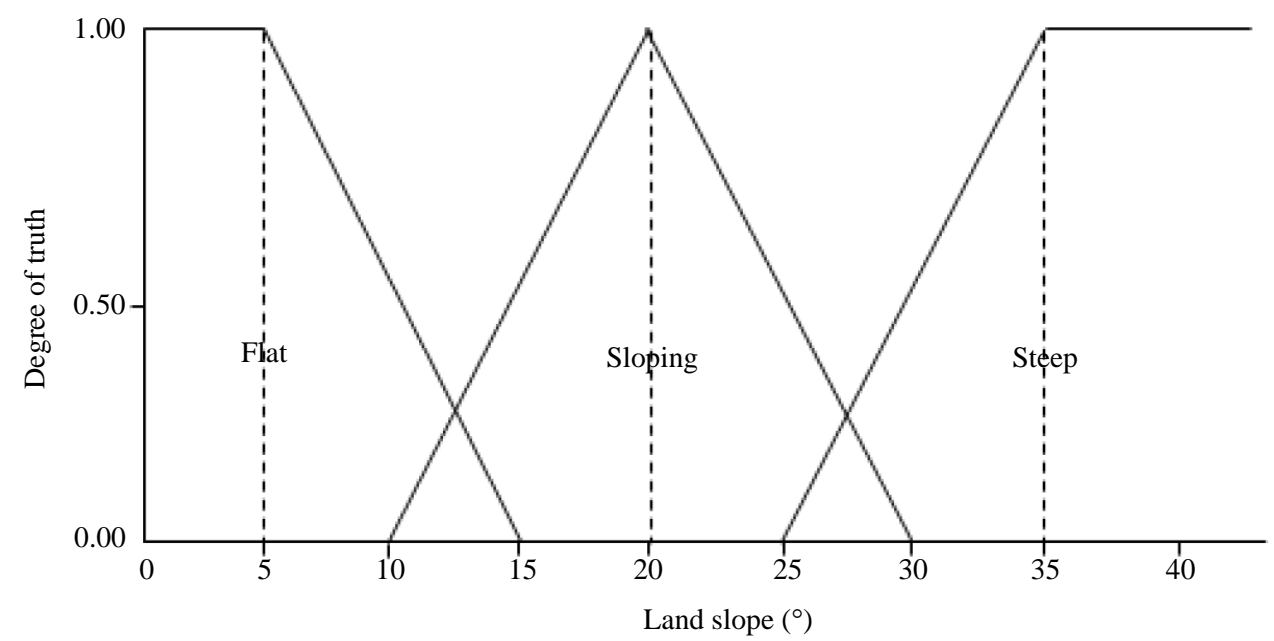

Fig. 5: The graph of fuzzy triangular membership function for land slope 


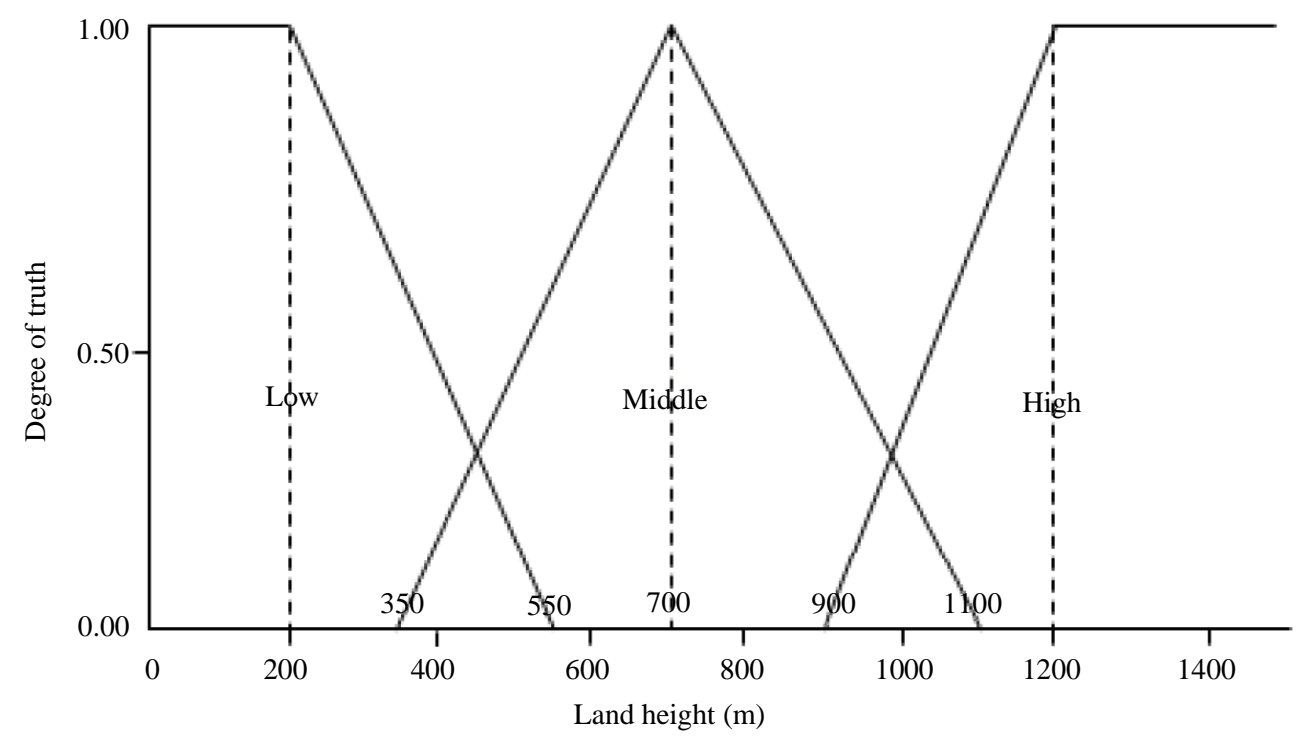

Fig. 6: The graph of fuzzy triangular membership function for land height

Table 1: Data example of four parameters rainfall, porosity, slop and height (in Fuzzy value)

\begin{tabular}{lllll}
\hline District & Rainfall & Porosity & Slope & Height \\
\hline Bireun & $0.13 \mathrm{~L}$ & $0.80 \mathrm{M}$ & $1.00 \mathrm{~F}$ & $0.86 \mathrm{M}$ \\
& $0.30 \mathrm{M}$ & & & \\
Asahan & $0.55 \mathrm{M}$ & $0.80 \mathrm{M}$ & $0.5 \mathrm{~F}$ & $1.00 \mathrm{~L}$ \\
Agam & $0.59 \mathrm{M}$ & $0.40 \mathrm{~S}$ & $1.00 \mathrm{~F}$ & $1.00 \mathrm{~L}$ \\
& & $0.30 \mathrm{M}$ & & \\
Kaur & $0.84 \mathrm{M}$ & $1.00 \mathrm{~S}$ & $1.00 \mathrm{St}$ & $1.00 \mathrm{~L}$ \\
Karawang & $0.52 \mathrm{M}$ & $0.70 \mathrm{M}$ & $0.50 \mathrm{Sl}$ & $1.00 \mathrm{~L}$ \\
$\ldots$ & $\ldots$ & $\ldots$ & $\ldots$ & $\ldots$ \\
\hline
\end{tabular}

Table 2: Data example of three parameters water availability, humadity and temperature (in Fuzzy value)

\begin{tabular}{llll}
\hline District & WA & H & T \\
\hline Bireun & 140.00 & 75.00 & 23.46 \\
Asahan & 140.00 & 75.00 & 26.46 \\
Agam & 140.00 & 75.00 & 23.75 \\
Kaur & 105.93 & 73.54 & 25.40 \\
Karawang & 140.00 & 75.00 & 26.52 \\
$\ldots$ & $\ldots$ & $\ldots$ & $\ldots$ \\
\hline
\end{tabular}

Moreover, three linguistic variables used to define the parameter Water Availability (mm) are Little (L), Middle (Mi) and Much $(\mathrm{Mu})$. They are represented by triangular points $(110,110,130),(120,140,160)$ and $(150,170,170)$ correspondingly. The configuration of its fuzzy triangular membership function is obviously depicted in Fig. 7.

Additionally, for identifying three fuzzy value possibilities of parameter Water Availability, 81 fuzzy rule bases are exploited. By using the fuzzy rule bases, the value of crisp output of the parameter Water Availability is used to calculate the Euclidean distance value (by combining with parameters Humidity and Temperature) then. Several examples of fuzzy rule base are explicitly expressed in Listing 1.

Two other parameters (besides parameter Water Availability) which directly influence to the fitness value are Temperature and Humidity. Here, such parameters are also configured via fuzzy triangular membership function. The parameter humidity (\%rh, it means \% relative humidity) is defined by three linguistic variables: Little (L), Middle (Mi) and Much $(\mathrm{Mu})$; where they are determined by triangular points $(60,60,70),(65,75,85)$ and $(80,90,90)$ respectively. The picture that illustrates the fuzzy triangular membership function of parameter Humidity is Fig. 8.

Likewise, the parameter Temperature $\left({ }^{\circ} \mathrm{C}\right)$ is also described by three linguistic variables; i.e., low, middle and high which are respectively characterized by L, M and $\mathrm{H}$. The fuzzy triangular boundaries used to depict the variables are $(5,5,15),(10,17.5,25)$ and $(20,30$, 30). Figure 9 noticeably tells the fuzzy triangular membership function for parameter Temperature.

The dummy data examples exercised for model's simulation is shown in the Table 1 and 2 . They all portray the geographical condition of 514 districts/municipalities of 34 provinces in Indonesia. The Table 1 presents information for geographical condition regarding parameters used for determining water availability. By using Fuzzy Mamdani approach, the value of water availability for each district is able to be identified. It is able to be seen that the value of four parameters are theoretically demonstrated in fuzzy value, where it exemplifies the degree value of truth for each parameter's value. 


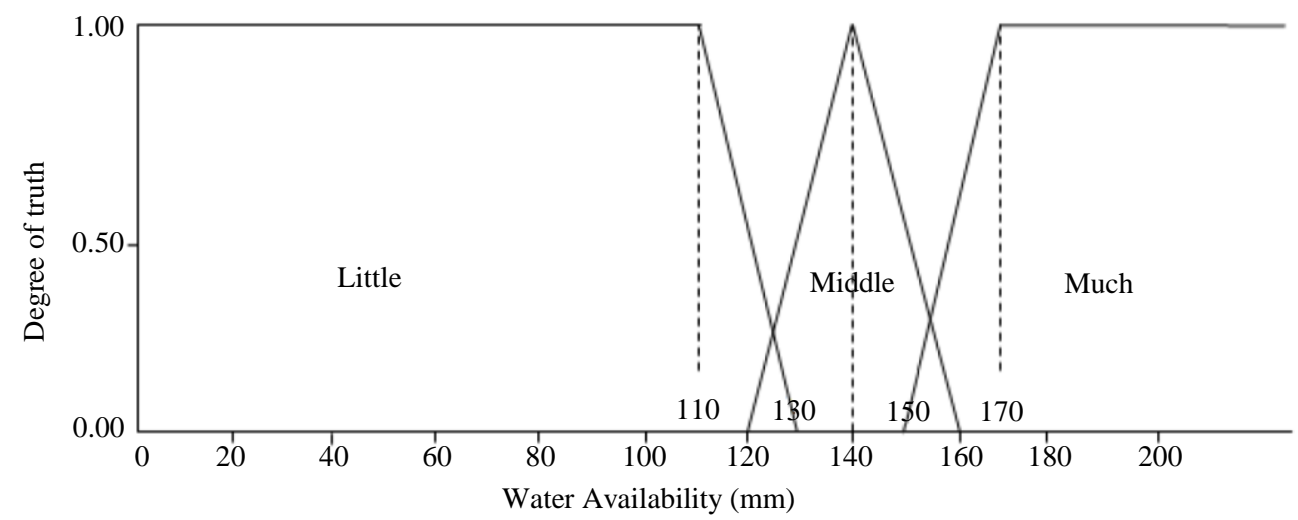

Fig. 7: The graph of fuzzy triangular membership function for water availability

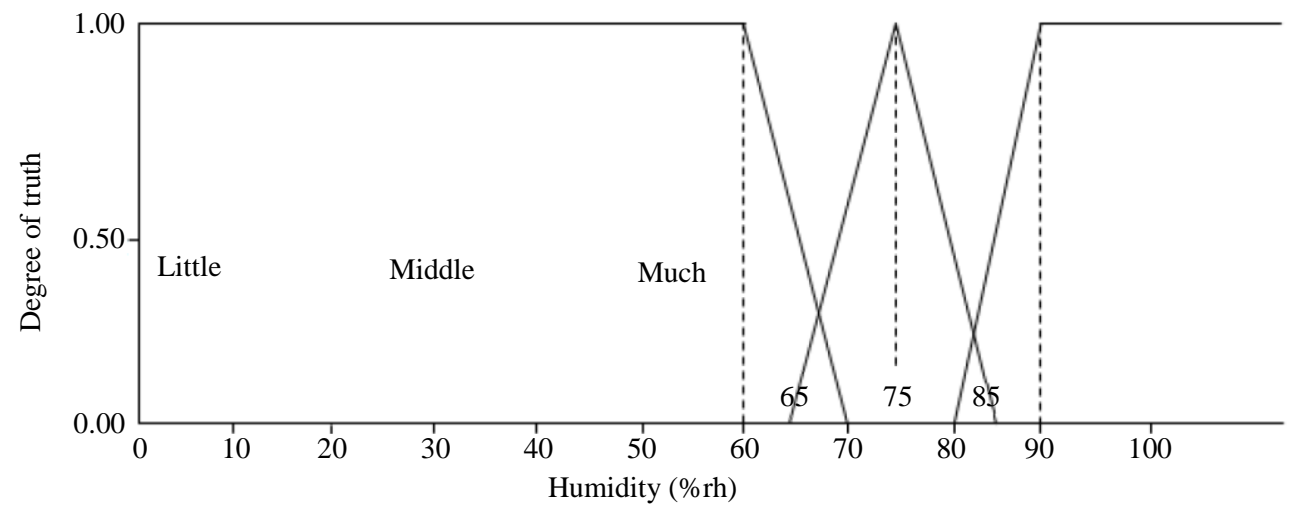

Fig. 8: The graph of fuzzy triangular membership function for humidity

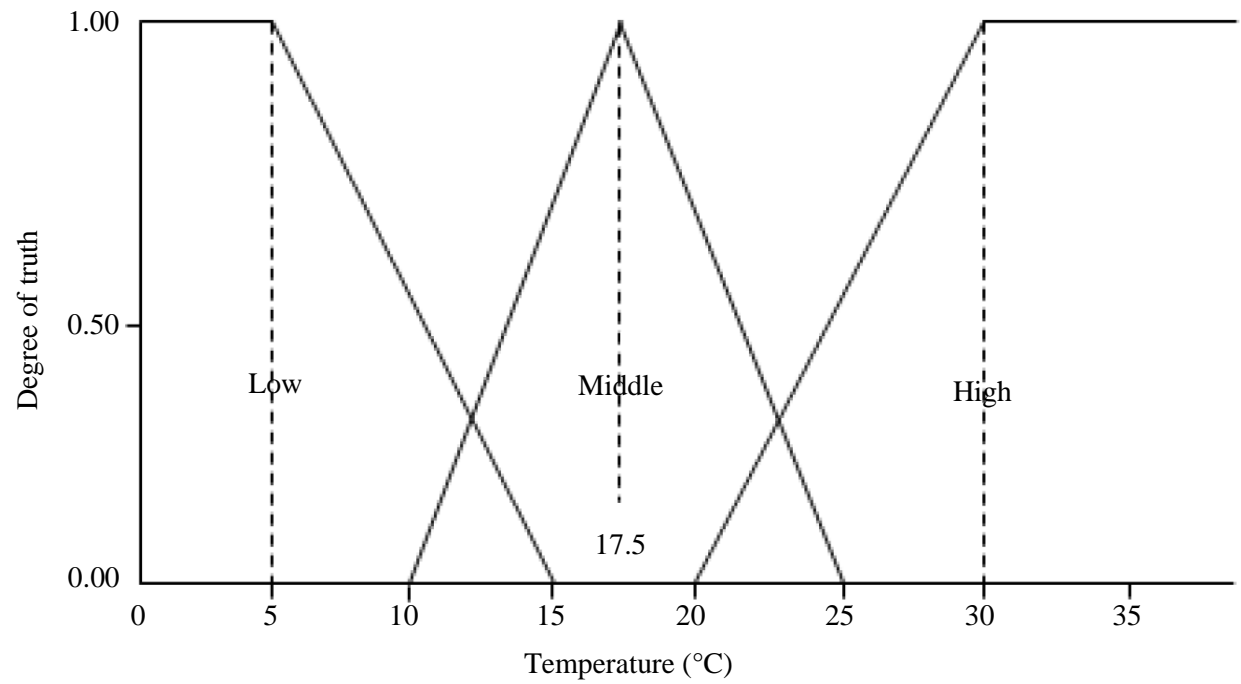

Fig. 9: The graph of fuzzy triangular membership function for temperature

Then, Table 2 undoubtedly displays the data examples of last three parameters; where WA represents a water availability, $\mathrm{H}$ characterizes a humidity and $\mathrm{T}$ symbolizes a temperature. They are illustrated in crisp output value; where it is coming from a calculation result based on fuzzy logic conception).

\section{The Constructed Model}

The relationships among entities in the constructed model is illustrated by class diagram in Fig. 10. Conceptually, the model consists of six entities/classes: Land, Crop, Fuzzy Logic, Membership Function, 
Euclidean Distance and Decision. The class Land and Crop respectively characterize entity and attributes of land and food crops. All attributes of each entity are defined in the second layer of each class. Particularly for the class Crop, the attributes express the ideal condition that crop can grow well. These attributes is going to be compared with land's attributes to find the distance which symbolizes the fitness value.

The class Fuzzy Logic is the center of model operation. Theoretically, it has four types of operation: extracting Data(), fuzzifying(), defuzzifying() and defining Parameter(). For four types of operation is going to be explained more detail in the part which explains Fig. 12 (the activity diagram). To do all operation in class Fuzzy Logic, the class Membership Function is ideally required. It portrays all attributes of the triangular membership function; i.e., $\mathrm{mfID}$ for representing an identity of triangular membership function, linguistic Variable expresses a linguistic variable, lowBound symbolizes a value of low boundary, midBound portrays a value of middle boundary and up Bound is signifying a value of upper boundary. The realization/implementation of class Membership Function has been strictly represented by Fig. 3 until 9 .
Finally, the result value of Euclidean distance calculation is recorded in attribute distance in the class Euclidean Distance, where it is done by operation calculating Distance(). As mentioned before, that the distance value symbolizes the fitness value between land and crop, thus realistically it is used to decide the objective decision. Then, the decision which is represented by listed distance values is produced by operation generating Decisioan() and represented in class Decision.

The high level composition of the constructed model is depicted by usecase diagram in Fig. 11. Principally, the model consists of four usecases: Fuzzy Parameterizing, Calculating Similarity, Generating Decision and Reporting. All parameters are processed via method fuzzy logic in the usecase Fuzzy Parameterizing. The actor who is responsible to this usecase is the human actor Department of Agriculture. The similarity gap between land and crop is computed in the usecase Calculating Similarity. Two actors are involved in this usecase, they are Climate-Data Org (as the system actor) who delivers all data and information required for operating the model and Department for Agriculture (the human actor) who operates the model humanly.

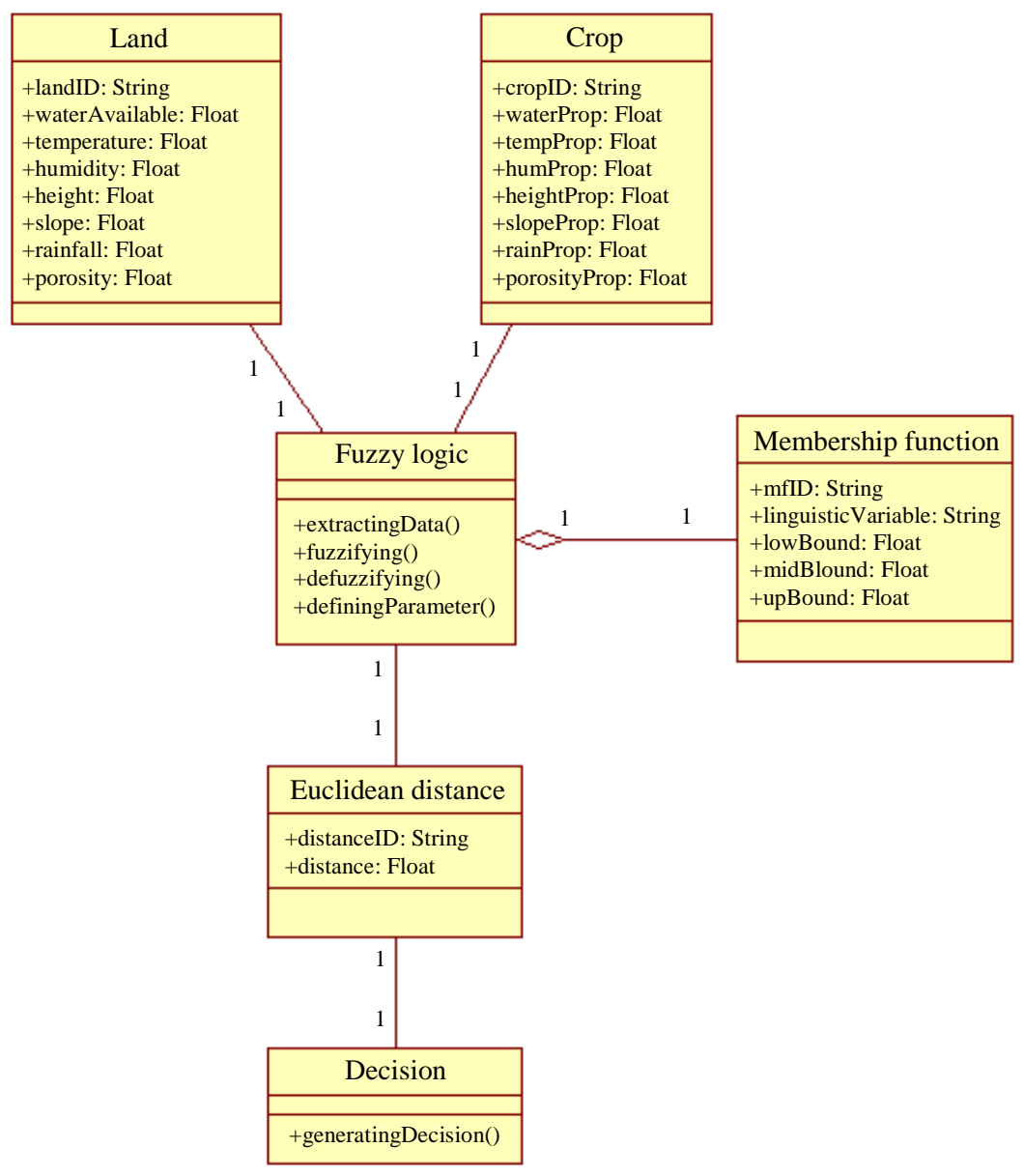

Fig. 10: The class diagram for the constructed model 


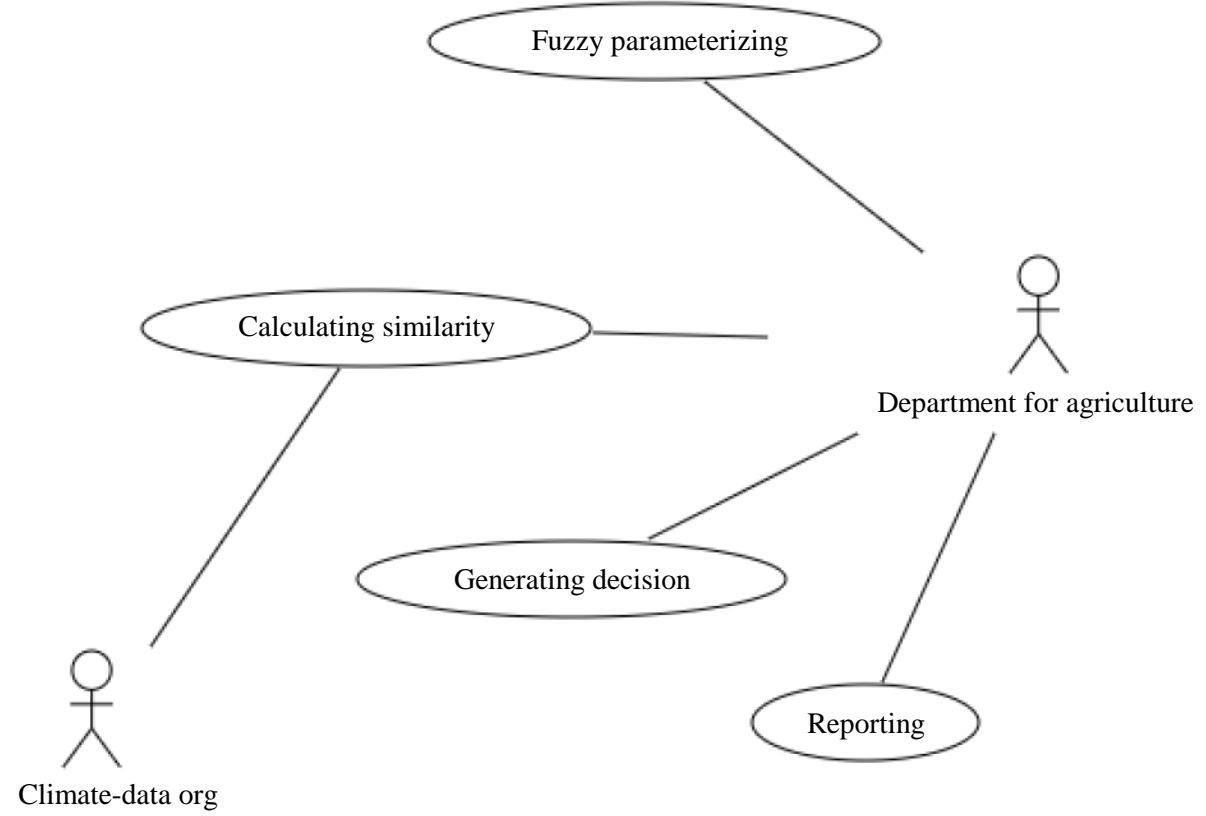

Fig. 11: The usecase diagram for the constructed model

Directly and automatically, the constructed model is able to generate the decision (where it is done in the usecase Generating Decision). The recommendation form based decision regarding the most proper food crop for specific area is proposed here. The propercombination list of area-crop (or land-crop) and all data and information necessitated are reported by the model via the usecase Reporting. The agriculture department of Indonesia Republic is the actor who has authority to both usecases.

In more detail, the Fig. 12 illustrates the processes/operations executed in three usecases (i.e., Fuzzy Parameterizing, Calculating Similarity and Generating Decision, please see blocked parts in Fig. 12) via the activity diagram. All data of 514 (100\% of Indonesian's districts) areas are extracted in process Extracting Data. The value of each parameter is converted to fuzzy value thru process Fuzzifying Parameters. Then, the value is converted again to crisp value (crisp output value) via process De-fuzzifying Parameters. Specifically in case, the parameter Water Availability is constructed thru fuzzy rule bases, it is done in the process/operation Defining Parameters.

The Euclidean distance for each combination landcrop is calculated in the process Calculating Distance. The distance value theoretically denotes the similarity value. That's why the process Calculating Distance is placed in the usecase Calculating Similarity. Here also, the value is converted to the relative value by implementing the Equation (3). It is purposely done to present that the best value (the fittest/the most proper) is normally indicated and symbolized by the highest value.
Finally, the model is able to find and then propose the most proper crop to land/area. The process to do so is process Selecting the Best. It is done in usecase Generating Decision.

The calculation for relative Euclidean distance value for each district and food plant was executed. The calculation result represents the fitness value between district VS food crops. The example graph of fitness value for five districts is obviously exhibited in Fig. 13. The highest value purposely symbolizes the most proper (fittest) food crop for the district. The example in Fig. 13 said that crop green bean is the most proper food crop to be practically planted in district areas Bireun, Asahan, Agam and Karawang; and peanut is the most proper food crop to be planted in district area Kaur.

Seven topographical parameters are considered to evaluate the condition of one agriculture area (planting land). The interconnection among parameters in the constructed model is configured thru the influence diagram (Fig. 2). Officially, four parameters (i.e., Rainfall, Land Porosity, Land Slope and Land Height) are functioned to directly determine water availability. Here, the parameter Water Availability is a dependent parameter, as it is determined based on other parameters. The parameter water availability with other two (i.e., Temperature and Humidity) are collaboratively functioned in the constructed model. In this case, the constructed model is going to advise the best combination between cropland and food crop which will be planted. 


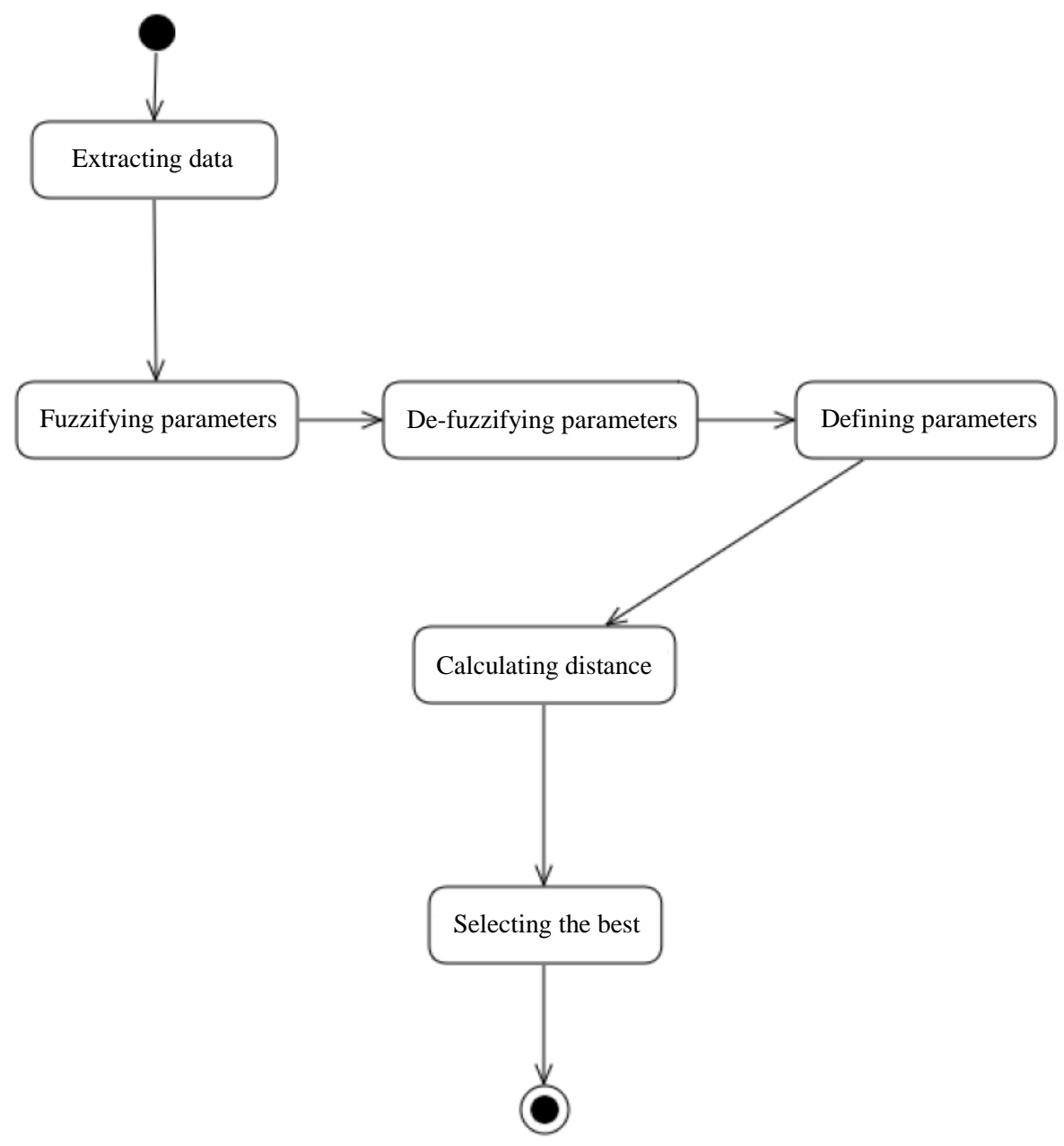

Fig. 12: The activity diagram for the constructed model

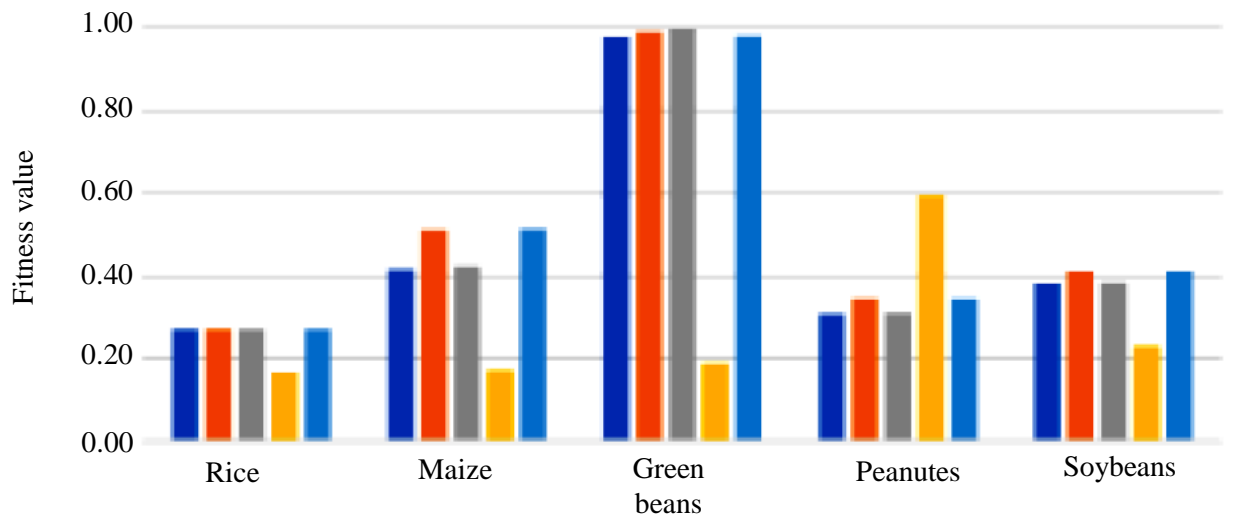

Food crops
Bireun
Asahan
Agam
Kaur
Karawang

Fig. 13: The example graph of fitness value for five districts 


\section{Discussion}

In this part, we would like to compare what we did and others. For example, comparing to what Chen et al. (2018) performed. Chen et al. (2018) developed a technique to draw cropping pattern, croplands and crop planted area in Brazil; explicitly for soy, cotton and maize. It was similar to our study result. In this study, we also constructed model to find the most proper food crop to be planted in the specific land. We found the most suitable combination crop-land in all area of Indonesia (in 514 districts of 34 provinces).

In conducting the study, Chen et al. (2018) functioned 2015-2016 time-series big data, we took as well approximately 93\% (big number of) single data to supply model data required. However, we practically required more types of crops, we used five types of food crop (i.e., rice, maize, soybeans, green beans and peanuts). Our proposed model also is able to technically read and adopt all types of time-series data (not only from a specific time range).

Chen et al. (2018) operated decision tree to classify cropping pattern. It is effectively able to extract croplands, cropping pattern and crop type by percentage of effectiveness were $90 \%, 73 \%$ and $86 \%$ respectively. Instead, regarding method of study, we functioned method fuzzy logic for parameterizing which combined to Euclidean distance in finding similarity value. Also, we did not calculate the effectiveness value, we only found the best combination of land-crop based on $93 \%$ empirical data. Nevertheless, the value showed that the land-crop combination could give the best effectiveness based on selected geographic and biotic parameters.

In addition, Bandara and Cai (2014) studied a correlation between climate change and food crop issue (price, productivity and its security). They made a model to observe the influence of climate change to crop productivity, food price and food security. We similarly exploited four types of parameter correlating to climate: rainfall, water availability, humidity and temperature. We technically operated them as we supposed they were the most imperative climate constraints to determine area for agriculture.

\section{Conclusion and Further Works}

A model based on the methods fuzzy logic and Euclidean distance to find the best combination landcrop in Indonesia was successfully created. The model is able to recommend the most appropriate food crop in one district. To assess it, seven geographic parameters were academically functioned; i.e., water availability, temperature, humidity, land height, land slope, rainfall and land porosity; where four parameters (i.e., land height, land slope, rainfall and land porosity) directly have an effect on water availability calculation.
The model was documented based on technical schemes of object oriented method. Three diagrams (i.e., class, usecase and activity diagrams) were fabricated to illuminate the constructed model in more detail. The interconnection of entities, communication pattern of actor-model and operation done in the model were well delivered thru such diagrams.

More than $90 \%$ empirical data was functioned to run model simulation and roughly $10 \%$ dummy data was generated via method Monte Carlo. The value of similarity of land-crops combination for 514 districts in Indonesia was provided. Thus, the authority institution is able to take an objective decision regarding planting strategy of food crops for future Indonesia food security.

The further study is required for measuring the food crop productivity. It is going to support for calculating the model effectiveness. Then, the study of correlation between model effectiveness and future food security is motivating to be done.

Moreover, other geographic parameters (e.g., population number, light radiation, land nutrition, etc.) are reasonably to be learned and involved in the model. They are possible to enrich the constructed model. Also, in fuzzy parameterizing, the expert (or multi experts) is able to be occupied to practically adjust the urgency level of parameters selected, where the level can be used to rationally epitomize the coefficient of parameters.

\section{Acknowledgement}

We would like to thank Bina Nusantara University who has supported and sponsored our studies and works, particularly Bina Nusantara Graduate Program, Master of Computer Science.

\section{Author's Contributions}

Ditdit Nugeraha Utama: Analyzing data and simulating and finalizing the model. He was also drafting and finalizing the manuscript.

Alvali Zaqi Taufan: Analyzing all data and designing and developing the model.

Al Ghifari Hartzani: Analyzing all data and developing the model.

Hasfhi Haidi: Analyzing all data and designing the model.

Yusuf Ramadhan Lubis: Analyzing and testing the model.

Wahyu Sardjono: Finalizing the manuscript.

\section{Ethics}

This manuscript substance is the authors' own original work and has not been previously published somewhere else. Authors already read and approved the manuscript and no potential ethical issues immersed. 


\section{References}

Abid, M., U.A. Schneider and J. Scheffran, 2016. Adaptation to climate change and its impact on food productivity and crop income: Perspectives of farmers in rural Pakistan. J. Rural Stud., 47: 254-266.

Anovitz, L.M. and D.R. Cole, 2015. Characterization and analysis of porosity and pore structures. Rev. Mineral. Geochem., 80: 61-164.

Anton, H., 1994. Elementary Linier Algebra. 7th Edn., John Wiley Sons.

Bandara, J.S. and Y. Cai, 2014. The impact of climate change on food crop security, food prices and food security in South Asia. Econ. Anal. Policy, 44: 451465.

Chen, W.C. and C.H. Wu, 2019. A trading decision support model to maximize the sustainability of a self-financed guaranteed farmgate price program. Comput. Electron. Agric., 158: 303-312.

Chen, Y., D. Lu, E. Moran, M. Batistella and L.V. Dutra et al., 2018. Mapping croplands, cropping patterns and crop types using MODIS time-series data. Int. J. Applied Earth Observ. Geoinform, 69: 133-147.

Dairaku, K., S. Emori and T. Oki, 2004. Rainfall amount, intensity, duration and frequency relationships in the Mae Chaem watershed in Southeast Asia. J. Hydrometeorol., 5: 458-470.

Echchelh, A., T. Hess and R. Sakrabani, 2018. Reusing oil and gas produced water for irrigation of food crops in drylands. Agric. Water Manage, 206: 124-134.

Han, E., W.E. Baethgen, A.V.M. Ines, F. Mer and J.S. Souza et al., 2019. SIMAGRI: An agro-climate decision support tool. Comput. Electron. Agric., 161: 241-251.

Khan, M.U., R.N. Malik and S. Muhammad, 2013. Human health risk from heavy metal via food crops consumption with wastewater irrigation practices in Pakistan. Chemosphere, 93: 2230-2238.

Kroese, D.P., T. Brereton, T. Taimre and Z.I. Botev, 2014. Why the monte carlo method is so important today. WIREs Comput. Stat., 6: 386-392.

Liu, J., T. Huffman and M. Green, 2018. Potential impacts of agriculture land use on soil cover in response to bioenergy production in Canada. Land Use Policy, 75: 33-42.

Ma, X., M. Mau and T.F. Sharbel, 2018. Genome editing for global food security. Trends Biotechnol, 36: 123-127.

Mamdani, E.H. and S. Assilian, 1975. An experiment in linguistic synthesis with a fuzzy logic controller. Int. J. Man-Mach. Studies, 7: 1-13.

Mathiassen, L., A. Munk-Madsen, P.A. Nielsen and J. Stage, 2000. Object-Oriented Analysis and Design. 1st Edn., Marko Publishing ApS, Aalborg Denmark.
Meinen, E., T. Dueck, F. Kempkes and C. Stanghellini, 2018. Growing fresh food on future space missions: Environmental conditions and crop management. Scientia Holticulturae, 235: 270-278.

Neethirajan, S., K.V. Ragavan and X. Weng, 2018. Agrodefense: Biosensors for food from healthy crops and animals. Trend Food Sci. Technol., 73: 25-44.

Noulas, C., M. Tziouvalekas and T. Karyotis, 2018. Zinc in soils, water and food crops. J. Trace Elements Med. Biol., 49: 252-260.

Osama, S., M. Elkholy and R.M. Kansoh, 2017. Optimization of the cropping pattern in Egypt. Alexandria Eng. J., 56: 557-566.

Pacetti, T., E. Caporali and M.C. Rulli, 2017. Floods and food security: A method to estimate the effect of inundation on crops availability. Adv. Water Res., 110: 494-504.

Richardson, J.J. and L.M. Moskal, 2016. Urban food crop production capacity and competition with the urban forest. Urban Forestry Urban Greening, 15: 58-64.

Rodda, N., L. Salukazana, S.AF. Jackson and M.T. Smith, 2011. Use of domestic greywater for small-scale irrigation of food crops: Effects on plants and soil. Phys. Chem. Earth, Parts A/B/C, 36: $1051-1062$.

Tai, A.P.K. and M.V. Martin, 2017. Impacts of ozone air pollution and temperature extremes on crop yields: Spatial variability, adaptation and implications for future food security. Atmospheric Environ, 169: 11-21.

Thompson, W. and S. Meyer, 2013. Second generation biofuels and food crops: Co-products or competitors? Global Food Security, 2: 89-96.

Topping, C.J., L. Dalby and J.W. Valdez, 2019. Landscape-scale simulations as a tool in multicriteria decision making to support agri-environment schemes. Agric. Syst., 176: 102671-102671.

Utama, D.N., F.A. Zaki, I.J. Munjeri and N. Putri, 2017a. FWFA optimization based decision support system for road traffic engineering. J. Phys. Conf. Series.

Utama, D.N., L.I. Lazuardi, H.A. Qadrya, B.M. Caroline and T. Renanda et al., 2017b. Worth eat: An intelligent application for restaurant recommendation based on customer preference (case study: Five types of restaurant in Tangerang Selatan region, Indonesia). Proceedings of the 5th International Conference on Information and Communication Technology, May 1719, IEEE Xplore Press, Malacca City, Malaysia. DOI: 10.1109/ICoICT.2017.8074654

Utama, D.N., F. Nuryasin, E.R. Nurbojatmiko and I. Qoyim, 2017c. DT: An Euclidean distance optimization based intelligent donation system model for solving the community's problem. J. Phys. Conf. Seri. 
Utama, D.N., M.D. Saputra, L.N. Wafiroh, M.A.A. Putra and P. Lestari, 2016. F-multicriteria based decision support system for road repair and maintenance (case study: Three areas in Tangerang Selatan, province Banten, Indonesia). Int. J. Manage. Applied Sci., 2: 171-175.

Wadhwa, S.S., K. Farahmand and K. Vachal, 2019. A deterministic mathematical model to support future investment decisions for developing inland container terminals. Res. Tran. Econ., 77: 100764-100764.

Wu, W., Q. Yu, L. You, K. Chen and H. Tang et al., 2018. Global cropping intensity gaps: In-creasing food production without cropland expansion. Land Use Policy, 76: 515-525.
Young, J.D., 2016. Forest measurements: An applied approach. Mt. Hood Community College.

Zadeh, L.A., 2008. Is there a need for fuzzy logic. Inform. Sci., 178: 2751-2779.

Zadeh, L.A., 2009. Toward extended fuzzy logic-a first step. Fuzzy Sets Syst., 160: 3175-3181.

Zadeh, L.A., 2015. Fuzzy logic-a personal perspective. Fuzzy Sets Syst., 281: 4-20. 